\title{
La belle indifférence revisited: a case report on progressive supranuclear palsy misdiagnosed as conversion disorder
}

This article was published in the following Dove Press journal:

Neuropsychiatric Disease and Treatment

2 August 2017

Number of times this article has been viewed

\author{
Petra J van Meerkerk- \\ Aanen' \\ Lars de Vroege ${ }^{1,2}$ \\ David Khasho' \\ Aziza Foruz' \\ J Thies van Asseldonk ${ }^{3}$ \\ Christina $M$ van der \\ Feltz-Cornelis ${ }^{1,2}$ \\ 'Clinical Center of Excellence for \\ Body, Mind, and Health, GGz Breburg, \\ ${ }^{2}$ Department Tranzo, Tilburg School \\ of Behavioral and Social Sciences, \\ Tilburg University, ${ }^{3}$ Department of \\ Neurology, Elisabeth Hospital, Tilburg, \\ the Netherlands
}

Background: Since the advent of computed tomography and magnetic resonance imaging scans, neurological disorders have less often been falsely labeled as conversion disorder (CD). However, misdiagnosis of a neurological disorder as CD still occurs, especially in cases with insidious onset. Misinterpretation of la belle indifférence may contribute to such misdiagnosis. Here, we describe a case of progressive supranuclear palsy/Richardson's syndrome (PSPS) misdiagnosed as a case of CD.

Case: A 62-year-old woman consulted two different neurologists in 2012 because of falling spells since 2009 and was diagnosed with CD. She was referred to the Clinical Center of Excellence for Body, Mind, and Health for treatment of CD. After neurological examination, blood tests, and psychiatric examination, in which la belle indifférence and a history of incest were found, $\mathrm{CD}$ was confirmed. However, despite treatment for $\mathrm{CD}$, the patient's physical symptoms deteriorated over a year. After repeated physical and psychiatric examinations, neurocognitive assessment, and consultation with a third neurologist because of suspicion of neurological disease, the patient was diagnosed with PSPS.

Conclusion: La belle indifférence may be a psychological sign in the context of $\mathrm{CD}$, but it may also be an expression of lack of mimic due to Parkinsonism or of eye movement disorder in the context of neurological illness. A diagnosis of CD should not be considered definitive if no improvement occurs in terms of physical, mental, and cognitive symptoms despite appropriate therapy. In case of deterioration, neurological reexamination and reinterpretation of la belle indifférence should be considered.

Keywords: conversion disorder, consultation, misdiagnosis, progressive supranuclear palsy, la belle indifférence, neurology

\section{Introduction}

Conversion disorder (CD), as stated in the Diagnostic and Statistical Manual of Mental Disorders, 5th edition (DSM-5), ${ }^{1}$ includes one or more deficits affecting either motor or sensory function that are incompatible with clinically recognized neurological or medical conditions, cannot be explained by any other medical or mental disorder, and cause clinically significant distress or impairment in occupational, social, or other important areas of functioning. The symptoms or deficits can be a sense of weakness or paralysis, abnormal movement (eg, tremor or myoclonus), swallowing or speech symptoms, seizure-like attacks, memory loss or anesthesia, special sensory symptoms, or mixed symptoms. CD can occur with or without a psychological stressor and is considered persistent if symptoms present themselves for over 6 months. ${ }^{1}$ The incidence and prevalence of $\mathrm{CD}$ in the community are unclear. ${ }^{2}$ The incidence of $\mathrm{CD}$ in
Correspondence: Lars de Vroege Clinical Center of Excellence for Body, Mind, and Health, Lage Witsiebaan 4, 5042 DA Tilburg, the Netherlands $\mathrm{Tel}+3 \mid 880161555$

Fax +31880161699

Email I.devroege@ggzbreburg.nl 
3,781 patients referred to the neurologists in Scotland was $6 \%{ }^{3}$ Misdiagnosis of an actual neurological disorder as CD was a frequent event until the 1970s.

In $1950,29 \%$ of patients diagnosed with CD were found to have a previously missed neurological disease at follow-up. This number of misdiagnosed patients decreased to $17 \%$ in 1960 and to 4\% in 1970 - a drop explained by the introduction of computed tomography $(\mathrm{CT})$ and magnetic resonance imaging (MRI) scans - and remained stable at that level., Nevertheless, misdiagnosis of CD can still occur, especially in the early stages of a neurological disorder. This has become more relevant with the introduction of DSM-5 for CD, in which a life event or trauma in relation to the onset of $C D$ is no longer required for classification. Since then, a tendency has been found to consider $\mathrm{CD}$ as a neurological disorder that can be established by a lack of clinical neurological findings and on the basis of a single neurological examination only. ${ }^{6}$ However, slowly progressive neurological disorders may need longer follow-up, consultation with a psychiatrist, or a multidisciplinary approach. ${ }^{7}$

Here, we describe a case of progressive supranuclear palsy/Richardson's syndrome (PSPS) misdiagnosed as CD. The patient presented to the Clinical Center of Excellence for Body, Mind, and Health as having CD, confirmed as such by two separate neurologists. However, she turned out to have PSPS after a year of treatment that led to improvement of her mental well-being but could not prevent physical and cognitive deterioration.

\section{Case}

A 62-year-old woman was referred to our outpatient clinic in February 2013, after visiting two different neurologists in 2012 who diagnosed her with CD, followed by an unsuccessful treatment episode in a rehabilitation clinic. The patient reported the following progressive problems since 2009: loss of power in the left arm and leg, and problems keeping her balance, sometimes resulting in a drunken gait and falling. In the 4 years before referral to our clinic, the patient had fallen spontaneously five times, without losing consciousness and with the ability to stand up immediately afterward. Furthermore, double vision occurred during fatigue, and the patient had difficulty articulating, difficulty finding words, pain in almost all joints and muscles, poor memory function, and difficulty in concentration due to which she could no longer read or solve puzzles - her favorite pastime. As a result, the patient experienced sleeping problems, low mood, no desire to perform activities, and a passive death wish.

In 2014, the patient again visited the neurological outpatient department. Anamnesis revealed progressive difficulties with speech and swallowing as well as falls due to balance disorder since 2009. On neurological examination, we saw a patient with a surprised look. Dysarthria was present, as well as a vertical upward supranuclear gaze palsy and slowing of downward vertical saccades. There was a prominent postural instability and a positive pull test. Snout reflexes were present. A left-sided striatal toe was seen. Rigidity and bradykinesia were present in legs more than arms. The applause sign was positive. Neither apraxia nor cortical sensory deficit was found, nor was there dysmetria or evidence of autonomic failure. Together with evidence of mesencephalon atrophy on MRI of the cerebrum and results on cognitive testing (described further), we concluded that the patient fulfilled the National Institute for Neurological Disorders and Stroke and Society for PSP criteria (NINDSSPSP) criteria for probable PSPS.

\section{Biography and treatment history}

For the past 10 years, the patient had suffered from mild depressive symptoms, for which she had received outpatient psychiatric treatment. In her childhood, between 12 and 18 years, the patient and her siblings had been victims of incest by an uncle, which her mother would not believe when she told her. The patient had received treatment for that issue and found good results, but she was still angry with her mother, and therefore, did not have contact with her anymore. She had been married for 10 years and had three children; one of her daughters developed borderline personality disorder (BPS). After 10 years, she went through a divorce because she found her husband insufficiently involved in the relationship. She later had another relationship, but her friend committed suicide, which came unexpectedly to her and was quite a shock. Since then, she lived alone and worked over her lifetime as a nurse in a general hospital. Now, she had retired. She still had contact with two of her children but was no longer in touch with her daughter who had BPS. Due to her physical symptoms, she received help at home and had fewer opportunities to pursue her hobbies. She was less outgoing for fear of falling. When she was younger, she used to consume alcohol, but she no longer did so.

The patient had been diagnosed with osteoarthritis, fibromyalgia, and recurrent bursitis of both hips for $>10$ years. She used irbesartan/hydrochlorothiazide 300/12.5 mg once daily for hypertension, which was well regulated.

For her current problems, the patient visited two neurologists in 2012, but they did not find any abnormalities on neurological examination, with the exception of insecure gait and transient coordination disturbances, which did not present as ataxia. In the first hospital, a CT scan of 
the brain and carotid duplex was done which revealed no pathology. In the second hospital, which she visited in 2012 for a second opinion, an MRI scan of the cerebrum showed small arachnoidal cysts in the left fossa medialis and MRI of the cervical spine showed slight degeneration with right paramedian HNP C6-C7 and median HNP C5-C6 without myelopathy. These findings could not explain the patient's symptoms; therefore, the most likely diagnosis appeared to be CD. This was discussed with the patient, and after treatment in a rehabilitation clinic did not produce results, she was referred to our center for treatment of CD.

\section{Family history}

The patient's mother and her daughter suffered from BPS. The patient and her siblings had suffered from incest by an uncle.

\section{Assessment at the Clinical Center of Excellence for Body, Mind, and Health}

\section{Physical examination}

In our center, two neurological examinations took place with a 2-month interval. In the first examination, the power of the left limbs was reduced, but this was no longer the case at the second examination. Her blood pressure was $160 / 85 \mathrm{mmHg}$. Screening blood tests were normal, and there were no indications of recent alcohol use. Levels of vitamins B1, B6, and B12 were elevated, for which the patient took supplements.

\section{Questionnaires/interview}

At intake and during treatment, an assessment was carried out using the Outcome Questionnaire (OQ), ${ }^{8}$ Patient Health Questionnaire (PHQ-9), ${ }^{9}$ Generalized Anxiety Disorder Scale (GAD-7),${ }^{10}$ Physical Symptom Scale (LKV-51), ${ }^{11}$ Short Form 36 Health Survey (SF-36), ${ }^{12}$ and Brief Pain Inventory (BPI). ${ }^{13}$ The scores are shown in Table 1.

Before the start of treatment, the scores on the OQ, PHQ-9, GAD-7, LKV-51, and BPI were 107, 20, 10, 27, and 3, respectively, and indicated above-average physical symptoms, significant pain, and inability to function in social roles, as well as major depressive disorder with concomitant anxiety disorder, or an anxious depression. The Mini International Neuropsychiatric Interview classification indicated a depressive episode. The Structured Clinical Interview for DSM Disorders-II (SCID II) interview showed avoidant personality characteristics.

\section{Psychiatric examination}

Psychiatric examination showed a friendly, elderly woman with a slightly unstable gait who made contact easily. Her facial expression was almost absent (Figure 1), and she discussed her symptoms with a somewhat surprised facial expression. The patient told us that she has always been like this, and it was part of her personality. Nevertheless, the surprised facial expression could be interpreted as la belle indifférence, but we could not be sure of it. Her speech was slightly monotonous without dysarthria.

Consciousness, attention, and concentration were normal during the examination despite her subjective complaints about concentration. No depersonalization or derealization was present. The patient did seem to dissociate several times for a short moment, that is, it seemed as if thinking became slow or stopped briefly a few times and was then resumed. Thinking and speech were slightly slow. Despite this, intelligence seemed normal. No psychotic symptoms were present. Mood seemed low, with a profound lack of affect. The patient was not suicidal.

\section{Differential diagnosis}

With these findings at assessment, the team discussed the following differential diagnostic considerations. There was a clear possibility of a neurological disorder, such as first signs of Parkinson's disease or epilepsy, which might contradict the diagnosis of $\mathrm{CD}$; however, such a neurological disorder had not been confirmed on neurological examinations, which included CT and MRI scans, so far.

Table I Routine outcome monitoring during treatment

\begin{tabular}{|c|c|c|c|c|c|c|c|c|c|c|}
\hline Test & Determinants measured by test & T0 & TI & T2 & T3 & T4 & T5 & T6 & T7 & $T$ end \\
\hline OQ & $\begin{array}{l}\text { Symptomatology, interpersonal } \\
\text { relationships, social role }\end{array}$ & 107 & - & 135 & 114 & 99 & 108 & 110 & 125 & 94 \\
\hline PHQ-9 & Depression 9 & 20 & 24 & 23 & 23 & 26 & 21 & 22 & 21 & 22 \\
\hline GAD-7 & Anxiety ${ }^{10}$ & 10 & 6 & - & 19 & 18 & 12 & 15 & 16 & 17 \\
\hline LKV-5I & Physical symptoms" & 27 & - & 41 & 42 & 20 & 13 & - & - & 14 \\
\hline SF-36 & General health functioning ${ }^{12}$ & - & - & - & - & 19 & 21 & 21 & 23 & 23 \\
\hline BPI & Severity of pain ${ }^{13}$ & 3 & - & - & 5 & 5 & 2 & - & - & 3 \\
\hline
\end{tabular}

Notes: “-" indicates missing value and/or that the specific questionnaire was not filled in at the specific time point. T0 was noted at initial examination. Follow-up $T$ assessments were conducted every 6 weeks.

Abbreviations: OQ, Outcome Questionnaire (cutoff $\geq 55$ ); PHQ-9, Patient Health Questionnaire (cutoff $\geq 10$ ); GAD-7, Generalized Anxiety Disorder (cutoff $\geq 10$ ); LKV-5I, Physical Symptom Checklist (Dutch abbreviation; cutoff $\geq 5$ ); SF-36, Short Form 36 Health Survey (cutoff $\geq 12$ ); BPI, Brief Pain Inventory (cutoff $\geq 3$ ). 


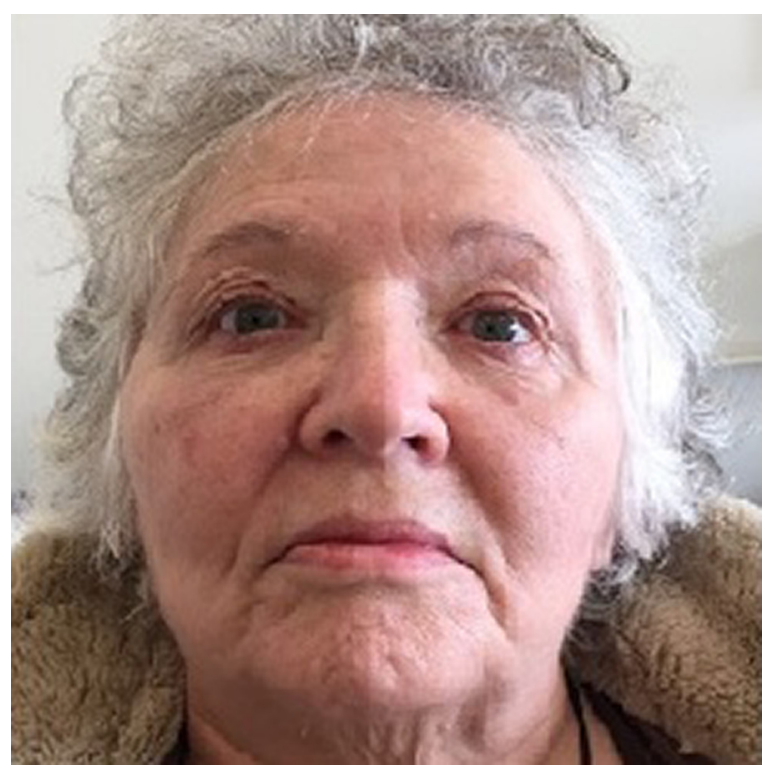

Figure I A photograph of the surprised facial expression of the patient.

The fact that the patient had suffered from an incest experience in her childhood might fit with a diagnosis of $\mathrm{CD}$, because a relationship between $\mathrm{CD}$ and childhood abuse has been found in previous studies, ${ }^{5,14}$ although, in DSM-5, incest is no longer considered necessary for or typical of CD. ${ }^{1,6}$ However, this experience had been well addressed in earlier treatment, and since then, the patient had lived for many decades without any signs of CD. Although she had anger issues toward her mother in relation to her incest experience, this was not a new development, and she had not suffered from significant related symptoms since then, unless the fibromyalgia, from which she had suffered for the last 10 years, is seen as a somatoform symptom. Although the patient did suffer from incest experiences in her youth, a divorce, and the loss of a friend by suicide in the past, there were no life events that could have been linked to the onset of her current physical symptoms.

The patient did suffer from avoidant personality characteristics, which are often seen in CD. The patient did suffer from depression that, per the questionnaires, was much worse than would seem at first glance on psychiatric examination. However, this would actually argue against a diagnosis of $\mathrm{CD}$, because in $\mathrm{CD}$, emotional symptoms are normally lacking in favor of neurological symptoms.

After careful consideration, despite some doubts because the neurological examinations did not yield an explanation and no clear actual psychological stressor could be identified, the patient received a working diagnosis of $\mathrm{CD}$. She was also diagnosed with major depression, a pain disorder, and a personality disorder not otherwise specified, with avoidant characteristics.

This was discussed with the patient, who accepted this diagnosis and was willing to start treatment, hoping that in this way, her symptoms would subside. Furthermore, because of the positive outcome of earlier treatment for her incest experience, she trusted that she would benefit from psychiatric treatment again.

\section{Treatment}

Acceptance and commitment therapy was started and aimed at the acceptance of her physical symptoms through enhancing psychological flexibility and exploring life values. Daytime activities and support with practical matters were discussed in treatment sessions. The patient received therapy for her anger issues with her mother in relation to the early incest experience. For her pain, treatment with pregabalin was started but discontinued because of adverse effects at low doses. A psychosomatic physical therapist guided her through improving her coordination.

During treatment in our outpatient clinic, which lasted for more than a year and with which she was compliant, the patient's anger toward her mother subsided, and she experienced better mental well-being. However, questionnaire monitoring as shown in Table 1 showed that depression, anxiety, physical symptoms, pain scores, and general health functioning (the SF-36) ${ }^{12}$ remained high. Moreover, a neuropsychological assessment (NPA) was performed because of lack of improvement after a year. The results of this NPA are shown in Table 2.

\section{Neuropsychological assessment}

There were no indications of malingering. Attention and memory were intact. However, there were indications of impairment in visuoconstruction and working memory, and there were clear deficits in information-processing speed and executive functioning, particularly within the domain of verbal fluency, that is, letter fluency. The patient showed clear mental slowness and difficulty discerning and communicating emotions, which was interpreted as sign of la belle indifférence. The slowness was interpreted as fitting with a depressive disorder, which explains the impaired informationprocessing speed, resulting in impaired verbal fluency. However, the profile might also fit neurological disorders.

This raised new suspicions because she also fell more often and had problems with swallowing and increased slowness of speech. Her physical symptoms deteriorated to such a degree that she could no longer visit our clinic or the 
Table 2 Neuropsychological assessment

\begin{tabular}{|c|c|c|}
\hline & Test & Test score \\
\hline Visuoconstruction & ROCFT - Copy ${ }^{65}$ & $30^{\mathrm{a}}$ \\
\hline Working memory & Digit Span (WAIS-IV) ${ }^{66}$ & $19^{a}$ \\
\hline \multirow[t]{7}{*}{ Memory } & RAVLT - Immediate recall ${ }^{67}$ & 40 \\
\hline & RAVLT - Delayed recall ${ }^{67}$ & 7 \\
\hline & RAVLT - Recognition ${ }^{67}$ & $29 / 30$ \\
\hline & RBMT - Immediate recall ${ }^{68}$ & 16 \\
\hline & RBMT - Delayed recall ${ }^{68}$ & 14 \\
\hline & ROCFT - Immediate recall ${ }^{65}$ & 17 \\
\hline & ROCFT - Delayed recall ${ }^{65}$ & 18 \\
\hline Information- & TMT-A ${ }^{69}$ & $58^{\mathrm{a}}$ \\
\hline \multirow[t]{3}{*}{ processing speed } & Symbol substitution (WAIS-IV) ${ }^{66}$ & $39^{a}$ \\
\hline & Stroop - Part $\mathrm{I}^{70}$ & $91^{b}$ \\
\hline & Stroop - Part II ${ }^{70}$ & $114^{\mathrm{b}}$ \\
\hline \multirow[t]{2}{*}{ Attention } & TMT-B ${ }^{69}$ & II I \\
\hline & Stroop - Part III ${ }^{70}$ & 167 \\
\hline Executive & Animal naming ${ }^{71}$ & $20^{\mathrm{a}}$ \\
\hline \multirow[t]{4}{*}{ functioning } & Letter fluency (“N” + “A”) & $\mathrm{II}^{\mathrm{b}}$ \\
\hline & Rule learning (BADS) $)^{72}$ & 4 \\
\hline & Key search test $(B A D S)^{72}$ & 2 \\
\hline & Zoo map test (BADS) ${ }^{72}$ & 2 \\
\hline Malingering & $\mathrm{TOMM}^{73}$ & $50 / 50$ \\
\hline
\end{tabular}

Notes: ${ }^{a} \leq 16$ th percentile; scores below the 16th percentile of normative data are considered below average (impairments). ${ }^{b} \leq 6$ th percentile; scores below the 6 th percentile are considered to correspond to neurocognitive deficits.

Abbreviations: ROCFT, Osterrieth Complex Figure Test; WAIS-IV, Wechsler Adult Intelligence Scale - fourth edition; RAVLT, Rey Auditory Verbal Learning Test; RBMT, Rivermead Behavioural Memory Test; TMT, Trail Making Test; BADS, Behavioral Assessment of the Dysexecutive Syndrome; TOMM, Test of Memory Malingering.

physical therapist. Her symptoms were reassessed during a house call by the psychiatrist and psychologist.

After discussion within the team and with the patient's general practitioner (GP), this course of events renewed suspicion of a neurological degenerative disorder despite the previous negative neurological findings, and a third neurologist was consulted by our center with the specific question to reconsider possible neurological disease as an explanation for the patient's physical symptoms.

\section{Neurological examination}

During the neurological examination, the patient's astonished look was noticed by the neurologist. Gaze was limited in the vertical plane, and vertical saccades were slowed (Figure 2). Pseudobulbar reflexes (snout) were present. Preservation of the oculocephalic reflex was also present (doll's eye phenomenon) at neurological examination (Figure 3). Bilateral bradykinesia as well as rigidity with axial predominance was present. There was severe postural instability. A leftsided striatal toe was seen. The applause sign was positive. The patient fulfilled the NINDS-SPSP clinical criteria for probable PSPS. ${ }^{16}$ MRI scans (from 2012 and 2014) showed marked atrophy of the mesencephalon, resulting in the so-called hummingbird sign (Figure 4), a finding that is considered characteristic of PSPS. ${ }^{17}$

\section{Evaluation of the patient}

After this diagnosis by the third neurologist, we discussed the findings with the patient. Although no cure was available for her illness, the patient considered therapy and close monitoring within our center useful as she had worked through some issues in the relationship with her mother and because, with the help of monitoring and neurological consultation that had been established by our center, a diagnosis that explained her symptoms had finally been made, and she was thankful for this. Treatment at our center was no longer needed, and the patient moved to a nursing home for extensive care.
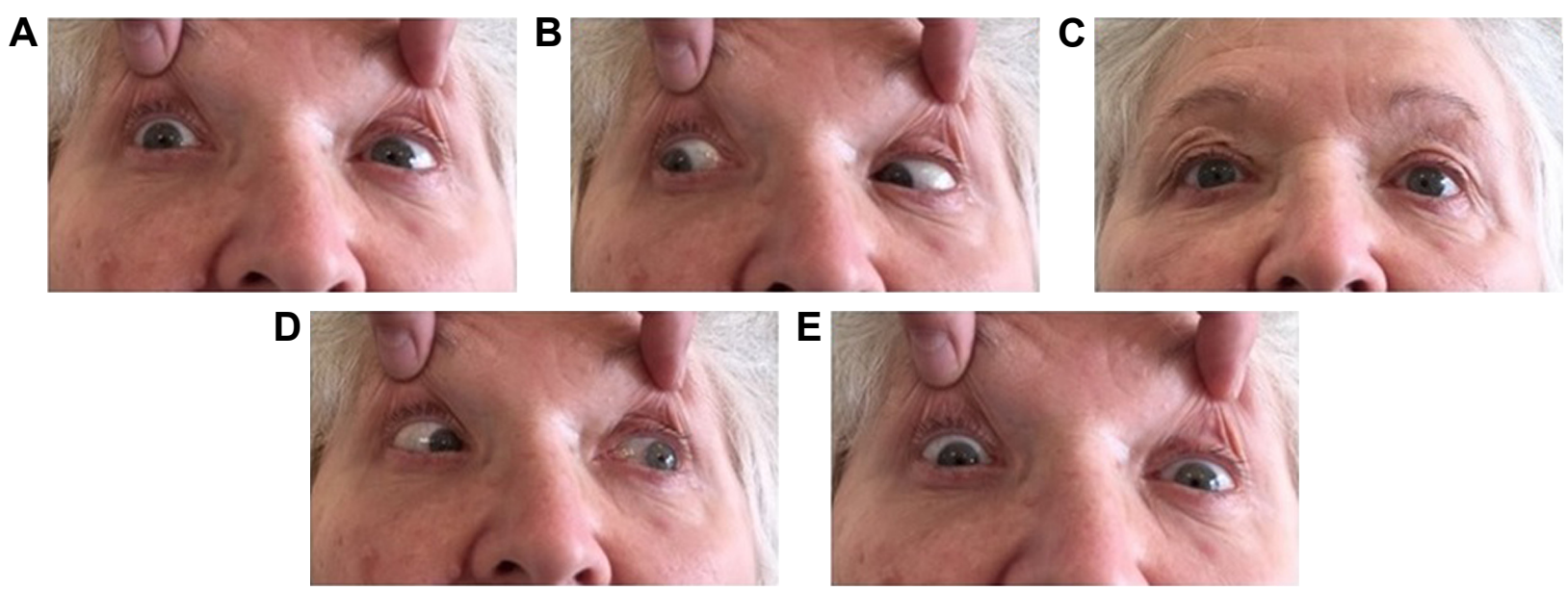

Figure 2 Directions of gaze that show limited range of voluntary eye movement. Up- and down-gaze are most severely affected in the patient.

Notes: (A) Patient is looking upward. (B) Patient is looking to her right. (C) Patient is looking forward. (D) Patient is looking to her left. (E) Patient is looking downward. 

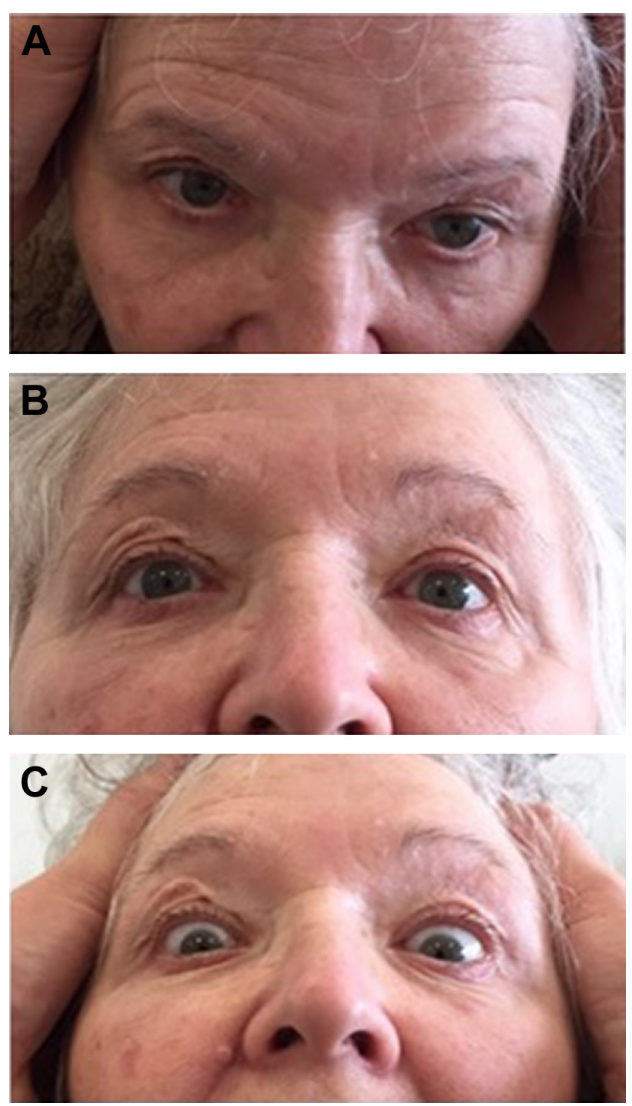

Figure 3 Example of eye reflex with fixation of gaze and examiner-led head motion (doll's eye) of the patient.

Notes: (A) Head is moved downward by the examiner. (B) Patient is looking straight. (C) Head is moved upward by the examiner.

\section{Discussion}

In this case, a 62-year-old woman had suffered from motor symptoms since 2009 , for which she had consulted two different neurologists in 2012, who assured her that there was no somatic explanation for her symptoms and that she suffered from CD. Nevertheless, in 2015, after unsuccessful treatment in a rehabilitation clinic and treatment for $\mathrm{CD}$ at our center with some improvement in mental well-being, on a third neurological examination and MRI scan taken 6 years after onset of symptoms, a diagnosis of PSPS was confirmed.

\section{Progressive supranuclear palsy}

Progressive supranuclear palsy (PSP) is a neurodegenerative disease first described in 1963 by Richardson et al. ${ }^{18}$ The reported prevalence and incidence of PSP vary from 1.3 to 4.9 and 0.3 to 1.1 per 100,000 persons, respectively. The disease affects both men and women. In 7\% of PSP cases, there is a positive family history. To date, other causes and risk factors are unknown. ${ }^{19}$

In the classic phenotype of PSP, one of the initial features is impaired balance, resulting in falls, mostly backward. Other early features are bradykinesia, personality changes, which are often subtle, and bulbar symptoms, such as dysphagia and dysarthria. Another important symptom is vertical gaze limitation, and hence the name of the disease. Especially, the down-gaze limitation is specific to the diagnosis of PSP. This limitation could be present in the early stage of disease, but could also develop at a later stage. However, the limitation is absent in 50\% of cases. Later symptoms of PSP are a stiff, broad-based gait; a standing posture due to axial rigidity; and a characteristic astonished facial expression. ${ }^{19}$ This astonished face could resemble la belle indifférence, a "relative lack of concern about the nature or implication of the symptoms", ${ }^{4,20}$ which has been thought to be related to $\mathrm{CD}$ in the past. ${ }^{21} \mathrm{La}$ belle indifférence is a rare phenomenon
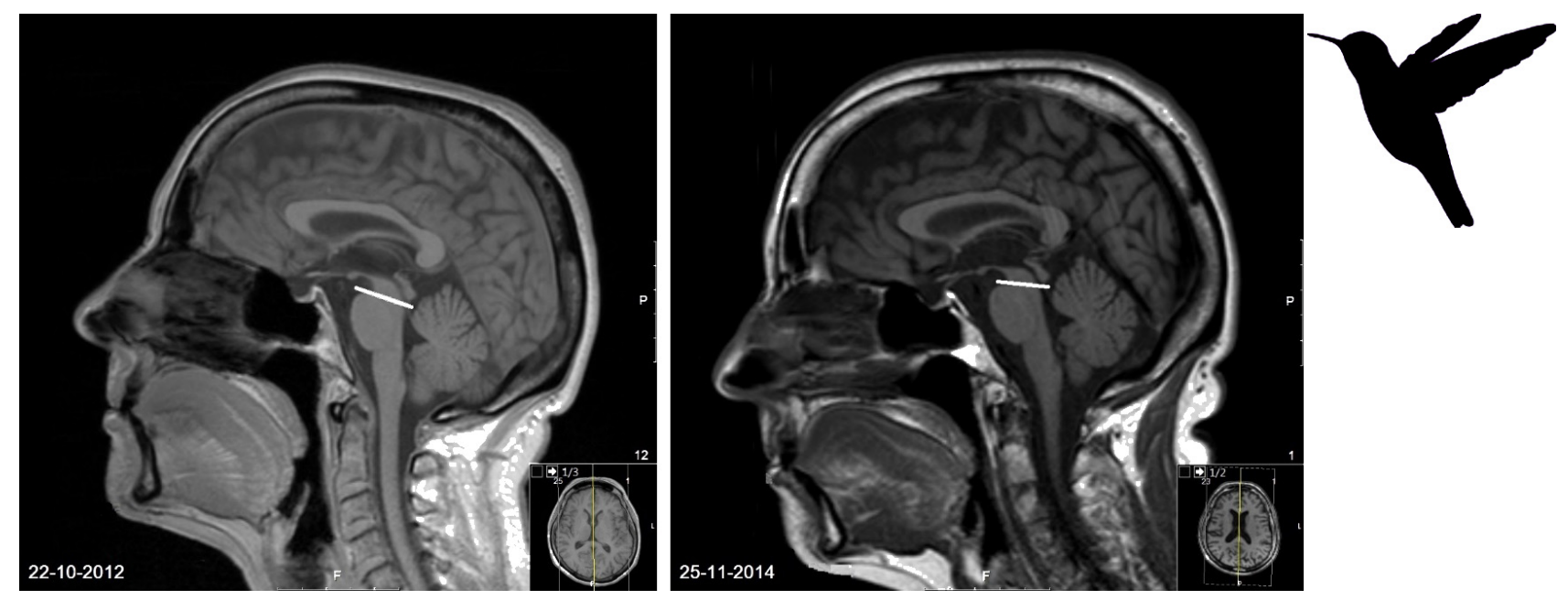

Figure 4 Hummingbird sign.

Notes: TI-weighted magnetic resonance imaging scan (taken in 2012 and 20I4) of the patient's brain showing selective atrophy of the midbrain with preservation of pons (divided by the white line), forming the silhouette of the head of the "hummingbird". This feature is called the hummingbird sign. 
and appears to be seen in organic diseases nearly as often as in CD. ${ }^{5,6}$ The validity of la belle indifférence in the diagnosis of CD has been disputed, ${ }^{22,23}$ and it has been mentioned in the context of several neurological disorders, including stroke, brain tumors, ${ }^{24}$ and epilepsy. ${ }^{25}$ In a systematic review of 11 studies, the median frequencies of la belle indifférence were $21 \%$ (range $0 \%-54 \%$ ) in 356 patients with conversion symptoms and $29 \%$ (range $0 \%-60 \%$ ) in 157 patients with organic disease, and it was suggested that la belle indifférence be abandoned as a clinical sign of CD. ${ }^{4}$ In this case, la belle indifférence was mentioned, as the patient lacked mimic and had a somewhat surprised look when she discussed her symptoms. Although a neurological explanation for this observation was also considered, it was dismissed because of the negative findings in the first two neurological examinations.

The above-mentioned symptoms belong to the classical form of PSP, PSPS. Nevertheless, it appeared that other syndromes might have the same histopathology of PSP with a different distribution in the brain. ${ }^{19}$ Besides PSPS, several other clinical phenotypes are considered as PSP: PSP-parkinsonism, corticobasal syndrome, pure akinesia with gait freezing, progressive nonfluent aphasia, dementia (frontotemporal or Alzheimer-like), cerebellar ataxia, and motor neuron disease. ${ }^{19}$ For example, $29 \%$ of patients with corticobasal syndrome appeared to have the histopathology of PSP. We do not explain these phenotypes further in this case report.

A definite PSP diagnosis can only be obtained postmortem by histopathological evidence of PSP pathology. When the patient is alive, PSPS is diagnosed on the basis of clinical criteria. The most frequently used criteria are the NINDSSPSP criteria developed under the guidance of the NINDSSPSP, which provides guidelines for a possible, probable, and definite diagnosis of PSP. ${ }^{16}$ Eye movement abnormalities and falls are of crucial importance for diagnosing PSPS per these guidelines. An MRI could be supportive as well, because it could reveal midbrain atrophy. On mid-sagittal images, this atrophy appears as a silhouette resembling a hummingbird, the so-called hummingbird sign. ${ }^{19}$ This sign is less visible on a CT scan. However, this sign may occur late during the disease. In contrast, midbrain atrophy was associated with PSP but not with PSP pathology in the absence of clinical PSPS, ${ }^{26}$ and the humming bird sign is therefore not always useful for an early diagnosis of PSP pathology. It is likely that atypical PSPS patients who lack evident motor symptoms may be referred to the psychiatric clinic rather than to the neurological clinic. There is no cure for PSPS. Dopamine can provide a short-term and modest improvement in the
PSP-parkinsonism phenotype. Other treatments are solely focused on symptom relief. ${ }^{19}$

\section{How to improve the diagnostic process}

This case shows that, despite close collaboration between (neuro)psychologists, neurologists, and psychiatrists, PSP can be initially misdiagnosed as CD. With the advent of the DSM-5, more emphasis has been placed on neurological examination, wherein the neurologist plays an important role. In hindsight, the patient had suffered from falls since 2009 , but no symptoms could be identified during the two neurological examinations in 2012. In 2013, only a slightly unstable gait was seen. Moreover, reevaluation of the MRIs of 2012 and 2014 showed midbrain atrophy (hummingbird sign). In 2013, the patient's surprised look was interpreted as la belle indifférence, whereas this may already have been an indication of eye movement abnormalities; however, this was not specifically tested at the time of the two neurological examinations in our center. It was only after further deterioration of her condition despite adequate treatment for $\mathrm{CD}$, a third neurological examination, and an MRI scan showing a hummingbird sign that the diagnosis of PSPS was established in 2015, 6 years after the onset of symptoms.

It should be noted that it is important to not only exclude neurological diseases but also find positive neurological indications that support the diagnosis of CD. ${ }^{6}$ There are neurological tests available with a high specificity for CD. ${ }^{27}$ When some of these tests are positive, misdiagnosis of CD becomes less probable. Nevertheless, not all conversion symptoms can be evaluated by these tests. ${ }^{7}$

There were doubts from the beginning about the classification of CD in this case, as discussed earlier, because of some contradictory findings during the psychiatric and psychological examination. In particular, the existence of depressive symptoms is unfamiliar in CD, because affect is dissociated and motor or other pseudo-neurological findings should dominate the clinical picture in CD.

Furthermore, there were no positive neurological signs in the sense of incompatibility with known neurological disorders in the first two neurological examinations; there were only signs of a fluctuating presence of symptoms, which can be seen not only in CD but also in several neurological disorders, especially at onset.

The NPA findings in this case showed seriously impaired verbal fluency, which is characteristic of PSPS according to the literature. ${ }^{28-36}$ Furthermore, the specific pattern of impairment within the domain of verbal fluency, namely, more impairment within letter fluency, was found as well. ${ }^{37,38}$ However, the NPA results of our patient showed overlap with 
cognitive impairments as found in depressive disorder, and she did suffer from a concomitant depressive disorder; hence, the interpretation as fitting a depressive disorder was made initially, and only later was the link with PSPS found. Depression is often diagnosed in cases of misdiagnosed PSPS, and this occurred in this patient as well. ${ }^{39}$

Studies on neurocognitive impairment in patients with depressive disorder suggest impaired functioning across multiple cognitive domains. ${ }^{40}$ More specifically, these domains include information-processing speed, ${ }^{40,41}$ concentration and attention, ${ }^{40,42}$ various domains of memory, ${ }^{40,42}$ and executive functioning. ${ }^{40,42}$ Thus, the comorbidity in this case made the NPA findings multi-interpretable.

Based on this case, some recommendations can be made: neurologists who intend to refute or establish a diagnosis of CD should not only look for neurological disorders but also look actively for neurological incompatibility of findings in the examination. If no incompatibility is found and neurological examination is without abnormalities, the neurological examination should be repeated when symptoms are progressive, to detect slowly progressive disorders. This may be combined with psychiatric treatment of concomitant mental disorders such as, in this case, depressive disorder, or to enable the patient to cope with physical symptoms as much as possible.

In the case of a finding of la belle indifférence in a psychiatric examination, specific testing of eye movement disorders should be performed, because la belle indifférence might be accompanied by eye movement disorders in the context of PSPS.

Burn and Lees emphasize that, in PSP, slowed cascades may precede gaze palsy, which often occurs rather late in the process. ${ }^{39}$ In the examination, therefore, in case of a surprised look, attention should be paid not only to gaze palsy but also to slowed cascades.

Because ophthalmologists have also been reported to miss PSP in cases of ophthalmological complaints, specific attention to this aspect is needed.

Psychiatrists might, therefore, consider consulting an experienced neurologist in such a case, because regular neurological examination by a non-neurologist, a GP, or an ophthalmologist may not include such tests, or they might have difficulty with the interpretation of the findings.

Another diagnostic consideration in la belle indifférence might be the presence of behavioral aspects such as lack of concern, which would fit with CD but not with PSPS. This patient was worried about her symptoms.

An NPA might be a supportive instrument in diagnosing PSPS because this case study confirms specific neurocognitive impairment in PSPS, consistent with the current literature about neurocognitive functioning in PSP. Cognitive and behavioral changes in PSP are very common and impair the quality of life in PSP. ${ }^{43}$ The percentage of patients who will show signs of dementia during the stages of disease varies from $10 \%$ to $70 \%$ in different studies..$^{29,30,44}$ In general, PSP is characterized by mainly frontal disturbances in the brain. ${ }^{45}$ Neurocognitive impairment in memory and attentional set shifting are found as well, but the most profound neurocognitive impairments mentioned in the literature are executive function deficits. ${ }^{28,46-50}$ Several studies report that verbal fluency is impaired in PSP. ${ }^{28-33}$ Within the domain of fluency, letter fluency is more impaired than semantic fluency. ${ }^{37,38,51,52}$ However, further studies are needed to replicate such a specific neurocognitive profile in PSP in order to justify the use of an NPA as supportive evidence for PSP. Previous studies showed specific neurocognitive impairment, mainly in verbal fluency and more specifically in letter fluency. ${ }^{37,38,51}$

Paying attention to the preferences of the patient for treatment, monitoring treatment outcomes, and taking physical symptoms seriously during mental health treatment are of paramount importance in the treatment of patients with doubtful CD/incipient neurological disorder, as can be seen in this case. Such an approach is a common practice in our center. ${ }^{53}$

Moreover, this case shows how close collaboration between (neuro)psychologists, psychiatrists, and neurologists can bear fruit in establishing a final diagnosis in case of doubt with regard to $\mathrm{CD}$. Although studies established psychiatric consultation with other medical specialists and GPs to be effective ${ }^{54,55}$ and clinical guidelines for such an approach exist, ${ }^{56,57}$ studies describing and evaluating the other direction, that is, consultation of neurologists by psychiatrists in the context of diagnosis and treatment of surmised CD, are lacking. In the past 5 years, several studies have emphasized the importance of clear communication by the neurologist in the diagnostic process in CD. ${ }^{6,58,59}$ However, it has been suggested that although neurologists do agree that psychological factors may play a role in CD, they often do not discuss this with the patient. ${ }^{60}$ In a recent survey in the Netherlands, neurologists and psychiatrists deemed collaboration between neurologists and psychiatrists in diagnosis and treatment of $\mathrm{CD}$ as being of prime importance. ${ }^{61} \mathrm{~A}$ small pilot study showed promising short-term results of bidirectional consultation in the diagnostic phase. ${ }^{62}$

The proportion of misdiagnosed patients with CD is $4 \%$. Moreover, misdiagnosis also occurs the other way around: $8 \%$ of patients diagnosed with multiple sclerosis appear to 
have CD. ${ }^{4}$ Furthermore, even among patients with established neurological disorders, $12 \%$ present with symptoms that are not fully explained by the neurological disease - a phenomenon called "functional overlay". In addition, the presence of a psychiatric history and an unusual neurological presentation have been the factors associated with misdiagnosis as CD. ${ }^{63}$ This may have been the case in our study, as the patient had a history of incest and suffered from a depressive disorder and avoidant personality characteristics. Other possible factors that have been identified as risk factors for misdiagnosis are the presence of an obvious life event and la belle indifférence; all these factors co-occurred in our patient. ${ }^{64}$

\section{Limitations}

Obviously, this is one case report, and further research would be needed to establish whether misdiagnosis with CD occurs more often in PSPS or if it is a general phenomenon in all neurological disorders with an insidious course.

\section{Strengths}

To our knowledge, this is the first case reporting a patient with PSPS who was diagnosed with a CD. This case description thoroughly describes the diagnostic path of a patient through several medical professions, the phenomenon of la belle indifférence, doll's eye phenomenon, and gaze palsy in a way that the clinical field can benefit from these findings. Although PSPS is a fairly rare condition, lessons can be learnt from this description.

\section{Research implications}

Although completely avoiding misdiagnosis in CD will be impossible in the near future, we can minimize the probability of misdiagnosis. It would be ideal to survey more risk factors for misdiagnosis in CD. For example, the relation between signs of la belle indifférence and eye movement disorders or lack of mimic might be the subject of research. This might enable clinicians to know the factors to be aware of in a patient with $\mathrm{CD}$. In the field of neuropsychology, more studies focusing on the neurocognitive component of PSPS should be devoted to different neurocognitive profiles in PSPS patients. A thoroughly described profile might contribute to better supportive evidence for diagnosis in an earlier phase of the disease.

\section{Conclusion}

This case shows that clinicians who are aware of possible somatic disease in patients diagnosed with CD and who collaborate closely can establish a diagnosis of a neurological disorder, even in a later phase. This is a good example of the benefits of a liaison between (neuro)psychologists, neurologists, and psychiatrists. In particular, when the physical situation of a patient deteriorates despite appropriate treatment of the CD, reassessment is recommended. Furthermore, a patient with a surprised look warrants investigation of saccades, and gaze should never be overlooked.

\section{Acknowledgment}

The details of the description of the patient in this case were modified to protect the patient's anonymity. The patient received treatment at the Clinical Center of Excellence for Body, Mind, and Health, GGZ Breburg, Tilburg, the Netherlands. The authors thank the patient for her consent to publish this article. Written consent is provided by the patient for publishing this article as well as for publishing her MRI scans and photographs of her gaze palsy and doll's eye phenomenon.

\section{Disclosure}

The authors report no conflicts of interest in this work.

\section{References}

1. American Psychiatric Association. Diagnostic and Statistical Manual of Mental Disorders, Fifth Edition (DSM-5). Washington, DC: American Psychiatric Association; 2013.

2. Carson AJ, Brown R, David AS, et al. Functional (conversion) neurological symptoms: research since the millennium. J Neurol Neurosurg Psychiatry. 2012;83(8):842-850.

3. Stone J, Carson A, Duncan R, et al. Who is referred to neurology clinics? the diagnoses made in 3781 new patients. Clin Neurol Neurosurg. 2010;112(9):747-751.

4. Stone J, Smyth R, Carson A, et al. Systematic review of misdiagnosis of conversion symptoms and "hysteria". BMJ. 2005;331:989.

5. Nicholson TR, Stone J, Kanaan RA. Conversion disorder: a problematic diagnosis. J Neurol Neurosurg Psychiatry. 2011;82(11):1267-1273.

6. Vermeulen M, Willems MHA. Conversiestoornis: van DSM-IV naar DSM-5 of van psychiatrische naar neurologische diagnose [Conversion disorder; from DSM-IV to DSM 5 or from psychiatric to neurological diagnosis]. Tijdschr Psychiatr. 2015;57(8):569-576. Dutch.

7. van der Feltz-Cornelis CM. De conversiestoornis in de DSM-5: what's in a name? [The conversion disorder in the DSM-5: what's in a name?]. Tijdschr Psychiatr. 2015;57:577-578. Dutch.

8. Lambert MJ, Morton JJ, Hatfield DR, et al. Administration and Scoring Manual for the OQ-45 (Outcome Questionnaire). 3rd ed. Wilmington, DE: American Professional Credentialling Services LLC; 2004.

9. Kroenke K, Spitzer RL, Williams JB. The PHQ-9. J Gen Int Med. 2001; 16(9):606-613.

10. Spitzer RL, Kroenke K, Williams JB, et al. A brief measure for assessing generalized anxiety disorder: the GAD-7. Arch Int Med. 2006;166: 1092-1097.

11. Hemert AV. Lichamelijke klachten vragenlijst [Physical Complaints Questionnaire]. Leiden: Leids Universitair Medisch Centrum; 2003. Dutch.

12. Ware JE Jr, Sherbourne CD. The MOS 36-item short-form health survey (SF-36): I. Conceptual framework and item selection. Med Care. 1992;30(6):473-483. 
13. Tan G, Jensen MP, Thornby JI, Shanti BF. Validation of the Brief Pain Inventory for chronic nonmalignant pain. J Pain. 2004;5(2):133-137.

14. Fava M, Rush AJ, Alpert JE, et al. Difference in treatment outcome in outpatients with anxious versus nonanxious depression: a STAR*D report. Am J Psychiatry. 2008;165(3):342-351.

15. Kranick S, Ekanayake V, Martinez V, Ameli R, Hallett M, Voon V. Psychopathology and psychogenic movement disorders. Mov Disord. 2011;26(10):1844-1850.

16. Litvan I, Agid Y, Calne D, et al. Clinical research criteria for the diagnosis of progressive supranuclear palsy (Steele-Richardson-Olszewski syndrome): report of the NINDS-SPSP international workshop. Neurology. 1996;47(1):1-9.

17. Kato N, Arai K, Hattori TJ. Study of the rostral midbrain atrophy in progressive supranuclear palsy. Neurol Sci. 2003;210(1-2):57-60.

18. Richardson JC, Steele JC, Olszewski J. Supranuclear ophthalmoplegia, pseudobulbar palsy, nuchal dystonia and dementia. Trans Am Neurol Assoc. 1963;88:25-29.

19. Colosimo C, Bak TH, Bologna M, Berardelli A. Fifty years of progressive supranuclear palsy. J Neurol Neurosurg Psychiatry. 2014;85(8): 938-944.

20. American Psychiatric Association. Diagnostic and Statistical Manual of Mental Disorders, Fourth Edition (DSM-IV). Washington, DC: American Psychiatric Association; 1994.

21. Rice DG, Greenfield NS. Psychophysiological correlates of la belle indifférence. Arch Gen Psychiatry. 1969;20(2):239-245.

22. Gould R, Miller BL, Goldberg MA, Benson DF. The validity of hysterical signs and symptoms. J Nerv Ment Dis. 1986;174(10):593-597.

23. Donohue A, Harrington C. La belle indifferénce: medical myth or useful marker of psychiatric disease. Med Health R I. 2001;84(6):207-209.

24. Stone J, Smyth R, Carson A, Warlow C, Sharpe M. La belle indifférence in conversion symptoms and hysteria: systematic review. $\mathrm{Br} \mathrm{J}$ Psychiatry. 2006;188:204-209.

25. Epilepsy - la belle indifférence? Lancet. 1987;1(8530):422-424.

26. Whitwell JL, Jack CR Jr, Parisi JE, et al. Midbrain atrophy is not a biomarker of progressive supranuclear palsy pathology. Eur J Neurol. 2013;20:1417-1422.

27. Daum C, Hubschmid M, Aybek S. The value of "positive" clinical signs for weakness, sensory and gait disorders in conversion disorder: a systematic and narrative review. J Neurol Neurosurg Psychiatry. 2014;85(2): 180-190.

28. O'Keeffe FM, Murray B, Coen RF, et al. Loss of insight in frontotemporal dementia, corticobasal degeneration and progressive supranuclear palsy. Brain. 2007;130:753-764.

29. Bensimon G, Ludolph A, Agid Y, et al. Riluzole treatment, survival and diagnostic criteria in Parkinson plus disorders: the NNIPPS study. Brain. 2009;132(1):156-171.

30. Pillon B, Dubois B, Ploska A, Agid Y. Severity and specificity of cognitive impairment in Alzheimer's, Huntington's, and Parkinson's diseases and progressive supranuclear palsy. Neurology. 1991;41(5):634-643.

31. Rittman T, Ghosh BC, McColgan P, et al. The Addenbrooke's Cognitive Examination for the differential diagnosis and longitudinal assessment of patients with parkinsonian disorders. J Neurol Neurosurg Psychiatry. 2013;84:544-551.

32. Brown RG, Lacomblez L, Landwehrmeyer BG, et al. Cognitive impairment in patients with multiple system atrophy and progressive supranuclear palsy. Brain J Neurol. 2010;133:2382-2393.

33. Soliveri P, Monza D, Paridi D, et al. Neuropsychological follow up in patients with Parkinson's disease, striatonigral degeneration-type multisystem atrophy, and progressive supranuclear palsy. J Neurol Neurosurg Psychiatry. 2000;69:313-318.

34. Frattali CM, Grafman J, Patronas N, Makhlouf F, Litvan I. Language disturbances in corticobasal degeneration. Neurology. 2000;54(4): 990-992.

35. Mathuranath PS, Xuereb JH, Bak T, Hodges JR. Corticobasal ganglionic degeneration and/or frontotemporal dementia? A report of two overlap cases and a review of literature. J Neurol Neurosurg Psychiatry. 2000;68(3):304-312.
36. Graham NL, Bak T, Patterson K, Hodges JR. Language function and dysfunction in corticobasal degeneration. Neurology. 2003;61(4): 493-499.

37. Bak TH, Rogers TT, Crawford LM, et al. Cognitive bedside assessment in atypical parkinsonian syndromes. J Neurol Neurosurg Psychiatry. 2005;76(3):420-422.

38. Lange KW, Tucha O, Alders GL, et al. Differentiation of parkinsonian syndromes according to differences in executive functions. $J$ Neural Transm (Vienna). 2003;110:983-995.

39. Burn DJ, Lees AJ. Progressive supranuclear palsy: where are we now? Lancet Neurol. 2002;1(6):359-369.

40. Rock P, Roiser J, Riedel W, Blackwell A. Cognitive impairment in depression: a systematic review and meta-analysis. Psychol Med. 2014; 44(10):2029-2040.

41. Tsourtos G, Thompson J, Stough C. Evidence of an early information processing speed deficit in unipolar major depression. Psychol Med. 2002;32(2):259-265.

42. Murrough JW, Iacoviello B, Neumeister A, Charney DS, Iosifescu DV. Cognitive dysfunction in depression: neurocircuitry and new therapeutic strategies. Neurobiol Learn Mem. 2011;96(4):553-563.

43. Schrag A, Selai C, Davis J, et al. Health-related quality of life in patients with progressive supranuclear palsy. Mov Disord. 2003;18(12): 1464-1469.

44. Daniel SE, de Bruin VM, Lees AJ. The clinical and pathological spectrum of Steele-Richardson-Olszewski syndrome (progressive supranuclear palsy): a reappraisal. Brain. 1995;118:759-770.

45. Fujioka S, Algom AA, Murray ME, et al. Similarities between familial and sporadic autopsy-proven progressive supranuclear palsy. Neurology. 2013;80(22):2076-2078.

46. Robbins TW, James M, Owen AM, et al. Cognitive deficits in progressive supranuclear palsy, Parkinson's disease, and multiple system atrophy in tests sensitive to frontal lobe dysfunction. J Neurol Neurosurg Psychiatry. 1994;57(1):79-88.

47. Paviour DC, Winterburn D, Simmonds S, et al. Can the frontal assessment battery (FAB) differentiate bradykinetic rigid syndromes? Relation of the FAB to formal neuropsychological testing. Neurocase. 2005; 11(4):274-282.

48. Grafman J, Litvan I, Gomez C, Chase TN. Frontal lobe function in progressive supranuclear palsy. Arch Neurol. 1990;47:553-558.

49. Burrell JR, Hodges JR, Rowe JB. Cognition in corticobasal syndrome and progressive supranuclear palsy: a review. Mov Disord. 2014;29(5): 684-693.

50. Gerstenecker A, Mast B, Duff K, et al. Executive dysfunction is the primary cognitive impairment in progressive supranuclear palsy. Arch Clin Neuropsychol. 2013;28(2):104-113.

51. Esmonde T, Giles E, Gibson M, et al. Neuropsychological performance, disease severity, and depression in progressive supranuclear palsy. J Neurol. 1996;243(9):638-643.

52. Rosser A, Hodges JR. Initial letter and semantic category fluency in Alzheimer's disease, Huntington's disease and progressive supranuclear palsy. J Neurol Neurosurg Psychiatry. 1994;57(11): 1389-1394.

53. van der Feltz-Cornelis C, Andrea H, Kessels E, Duivenvoorden H, Biemans H, Metz M. Shared decision making in combinatie met ROM bij patiënten met gecombineerde lichamelijke en psychische klachten; een klinisch-empirische verkenning [Shared decision making in combination with ROM in patients with combined physical and psychological symptoms: a clinical-emperical exploration]. Tijdschrift voor Psychiatrie. 2014;56(6):375-384. Dutch.

54. Leentjens AF, Boenink AD, van der Feltz-Cornelis CM. Can we increase adherence to treatment recommendations of the consultation psychiatrist working in a general hospital? A systematic review. J Psychosom Res. 2010;68(3):303-309.

55. van der Feltz-Cornelis CM, van Os TW, van Marwijk HW, Leentjens AF. Effect of psychiatric consultation models in primary care. A systematic review and meta-analysis of randomized clinical trials. J Psychosom Res. 2010;68(6):521-533. 
56. Leentjens AF, Boenink AD, Sno HN, et al; for Netherlands Psychiatric Association. The guideline "consultation psychiatry" of the Netherlands Psychiatric Association. J Psychosom Res. 2009;66(6):531-535.

57. Leentjens AF, van derFeltz-Cornelis CM, Boenink AD, van Everdingen JJ. Richtlijn "Consultatieve psychiatrie" van de Nederlandse Vereniging voor Psychiatrie voor consulten in de eerste lijn en in de ziekenhuissetting [The practice guideline "Consultation psychiatry" of the Dutch Psychiatric Association for psychiatric consultations in primary care and the hospital]. Ned Tijdschr Geneeskd. 2008;152(35):1914-1917. Dutch.

58. Stone J. Functional neurological disorders: the neurological assessment as treatment. Neurophysiol Clin. 2014;44(4):363-373.

59. Dubas F, Thomas-Antérion C. Symptômes somatomorphes en consultation de neurologie: expression, soubassement et occasion: étude rétrospective de 124 situations [Somatoform disorders in neurology visits: history and circumstances: retrospective study of 124 cases]. Rev Neurol (Paris). 2012;168(12):887-900. French.

60. Kanaan RA, Armstrong D, Wessely SC. Neurologists' understanding and management of conversion disorder. J Neurol Neurosurg Psychiatry. 2011;82(9):961-966.

61. de Schipper LJ, Vermeulen M, Eeckhout AM, Foncke EM. Diagnosis and management of functional neurological symptoms: the Dutch experience. Clin Neurol Neurosurg. 2014;122:106-112.

62. Hubschmid M, Aybek S, Maccaferri GE, et al. Efficacy of brief interdisciplinary psychotherapeutic intervention for motor conversion disorder and nonepileptic attacks. Gen Hosp Psychiatry. 2015;37(5):448-455.

63. Stone J, Carson A, Duncan R, et al. Which neurological diseases are most likely to be associated with "symptoms unexplained by organic disease". J Neurol. 2012;259(1):33-38.
64. Stone J, Reuber M, Carson A. Functional symptoms in neurology: mimics and chameleons. Pract Neurol. 2013;13:104-113.

65. Osterrieth P. Le test de copie d'une figure complexe: contribution à l'étude de la perception et de la mémoire [The test of copying a complex figure: a contribution to the study of perception and memory]. Arch Psychol. 1944;30:206-356. French.

66. Wechsler D. Wechsler Adult Intelligence Scale - Fourth Edition (WAIS-IV). San Antonio, TX: NCS Pearson; 2008.

67. Saan R, Deelman B. De 15-WoordenTest A (Manual). Groningen: Department of Neuropsychology, University of Groningen; 1986.

68. Wilson BA, Cockburn J, Baddeley AD. The Rivermead Behavioural Memory Test. London: Pearson Assessment; 1985.

69. Reitan RM. Trail Making Test: Manual for Administration and Scoring. Tucson: Reitan Neuropsychology Laboratory; 1992.

70. Stroop JR. Studies of interference in serial verbal reactions. $J$ Exp Psychol. 1935;18(6):643-662.

71. Deelman B, Koning-Haanstra M, Liebrand W, van der Burg W. Een afasie-test voor auditief taalbegrip en mondeling taalgebruik. Handleiding [An Aphasia Test for Auditive Language and Oral Language. Instruction Manual]. Lisse: Swets \& Zeitlinger; 1981. Dutch.

72. Wilson BA, Alderman N, Burgess PW, Emslie H, Evans JJ. Behavioural Assessment of the Dysexecutive Syndrome. St Edmunds: Thames Valley Test Company; 1996.

73. Tombaugh TN, Tombaugh PW. Test of Memory Malingering: TOMM North Tonawanda, NY: Multi-Health Systems; 1996.
Neuropsychiatric Disease and Treatment

\section{Publish your work in this journal}

Neuropsychiatric Disease and Treatment is an international, peerreviewed journal of clinical therapeutics and pharmacology focusing on concise rapid reporting of clinical or pre-clinical studies on a range of neuropsychiatric and neurological disorders. This journal is indexed on PubMed Central, the 'PsycINFO' database and CAS,

\section{Dovepress}

and is the official journal of The International Neuropsychiatric Association (INA). The manuscript management system is completely online and includes a very quick and fair peer-review system, which is all easy to use. Visit http://www.dovepress.com/testimonials.php to read real quotes from published authors. 